\title{
PENGARUH VARIASI INTERSLICE GAP TERHADAP KUALITAS CITRA DAN INFORMASI CITRA ANATOMI PADA MRI BRAIN POTONGAN AXIAL T1WI SPIN ECHO
}

\author{
M. Ainul Mala ${ }^{1)}$, Luthfi Rusyadi ${ }^{2)}$, Sudiyono ${ }^{3)}$ \\ 1,2,3) Poltekkes Kemenkes Semarang \\ e-mail : ainulmala47@gmail.com
}

\begin{abstract}
Background : Interslice gap is the distance between slices, usually its value is based on the percentage of slice thickness, interslice gap is one of the parameters that can affect the quality of MRI image. Rarely are radiographers willing and able to manipulate the value of the interslice gap, so it can produce a good image. The purpose of this study is, to determine the effect of interslice gap variation on quality on MRI brain pieces axial T1WI spin echo, to know the difference of interslice gap variation to anatomical image information on MRI brain T1WI spin echo axial, to know the value of interslice gap which has an optimal anatomical image information on MRI brain T1WI spin echo axial.

Methods : This type of research is quantitative and qualitative with an experimental approach. The research was conducted at the General Hospital of dr. Sardjito Yogyakarta. The data were 32 images of MRI brain T1WI spin echo from the variation of interslice gap used $0 \%, 10 \%, 20 \%$, and $30 \%$ from slice thickness $5 \mathrm{~mm}$. The test was performed on image quality that was statistically analyzed by linear regression test. While for information of anatomical image analyzed with Friedman test, from friedman test can be known information of best anatomical image, seen from mean rank.

Results : The results of this study indicate that there is an effect of interslice gap variation on quality on MRI brain of T1WI spin echo axial pieces, seen from p value of SNR $(0.010)$ and CNR $(0.001)<0.05$. In addition there is influence, there is also differences in anatomical image information on MRI brain pieces axial T1WI spin echo, seen from $\mathrm{p}$ value that is $0.001<0.05$. seen from the mean rank interslice gap $10 \%$ has the best anatomical image information.

Conclusion : There is an effect of interslice gap on image quality on MRI brain axial of T1WI spin echo, there is difference of MRI brain anatomical image information of T1WI spin echo axial with interslice gap variation, interslice gap $10 \%$ value has the most optimal information.
\end{abstract}

Keywords : Interslice gap, Image quality, Anatomical image information

\section{Pendahuluan}

Menurut Westbrook (2014), kualitas gambar ditentukan oleh Signal to noise ratio (SNR), Contrast to noise ratio (CNR), Spatial resolution dan Scan time. Pemilihan parameter diupayakan agar gambar yang dihasilkan optimal dan waktu scanning yang singkat. Optimisasi pemeriksaan MRI sangat perlu diketahui oleh seorang radiografer dengan cara mengetahui faktor-faktor yang mempengaruhi kualitas gambar, cara memanipulasi parameter yang ada pada pesawat MRI dan cara menghasilkan gambar yang optimal.

Salah satu parameter yang dapat mempengaruhi kualitas citra, khususnya SNR dan CNR yaitu interslice gap, dengan menaikkan interslice gap maka SNR akan meningkat. Munurut Brown dan Semelka (2003), interslice gap yaitu jarak antar slice. Interslice gap dapat mengkompensasi pulsa eksitasi radio frequency (RF) yang tidak sempurna. Jika slice saling berdekatan (interslice gap rendah), pulsa eksitasi yang diaplikasikan pada posisi yang berdektan sebagian overlap dan mengeksitasi jaringan yang sama karena menggambarkan slice eksitasi yang tidak seragam, situasi ini disebut cross-talk. Cross-talk memberi efek saturasi pada area slice yang overlap dan menghasilkan sedikit sinyal yang terdeteksi. Jarak antar slice mengurangi tingkat cross-talk.

Menurut Hasemi (2010), penggunaan interslice gap yang besar memungkinkan lesi yang kecil tidak terlihat dengan baik, karena lesi tersebut berada pada slice gap itu sendiri. 
Menurut Hari, dkk.(2016) pemeriksaan MRI brain potongan axial dengan parameter interslice gap yang digunakan yaitu 1,5 $\mathrm{mm}$ atau $30 \%$ dari nilai slice thickness $(5$ mm). Sedangkan, menurut Ellingson, dkk. (2015) pada pemeriksaan mri brain potongan axial tidak diberi jarak (interslice gap) atau $0 \%$ dengan slice thickness yang digunakan yaitu $5 \mathrm{~mm}$.

Berdasarkan studi pendahulu penulis di RSUP Dr. Sardjito Yogyakarta, penulis mangamati bahwa dalam melaksanaan pemeriksaan MRI brain, radiografer tidak pernah mengatur nilai interslice gap dan lebih terpaku pada protokol yang sudah ada, nilai interslice gap untuk potongan axial yang digunakan yaitu $1 \mathrm{~mm}$ atau $20 \%$ dari slice thickness yang digunakan $(5 \mathrm{~mm})$. Penulis juga telah melakukan variasi interslice gap $0 \%, 10 \%, 20 \%$ dan $30 \%$ dari slice thickness $5 \mathrm{~mm}$, lalu menanyakan kepada dokter radiolog mengenai perbedaan informasi yang dihasilkan. Menurut radiolog terdapat perbedaan secara visual.

Tujuan dari penelitian ini adalah untuk mengetahui pengaruh variasi interslice gap terhadap kualitas pada MRI brain potongan axial T1WI spin echo, perbedaan variasi interslice gap terhadap informasi citra anatomi pada MRI brain potongan axial T1WI spin echo. Serta untuk mengetahui nilai interslice gap yang memiliki informasi citra anatomi optimal pada MRI brain potongan axial T1WI spin echo.

\section{Metode}

Jenis penelitian ini adalah penelitian kuantitatif dan kualitatif dengan pendekatan eksperimental untuk membandingkan nilai signal to noise ratio (SNR), contrast to noise ratio (CNR), dan informasi citra anatomi pada variasi nilai interslice gap. Sampel penelitian ini adalah 8 sukarelawan, kemudian masing-masing sukarelawan dilakukan pemeriksaan MRI brain dengan variasi interslice gap $0 \%, 10 \%, 20 \%$, dan $30 \%$ dari slice thickness yang akan digunakan yaitu $5 \mathrm{~mm}$, dengan sekuens pulsa spin echo pembobotan T1 potongan axial.

Pengukuran SNR dibantu dengan automatic software yang ada pada pesawat MRI tersebut dengan cara menentukan region of interest (ROI). ROI diletakkan pada daerah dari ventrikel lateral, thalamus, nucleus caudatus, putamen, dan capsula interna yang tampak di monitor komputer, sehingga akan mendapatkan nilai SNR dari signal organ tersebut. Untuk noise, yang di ROI adalah daerah bebas (background) luar gambaran obyek brain agar mendapatkan nilai dari noise. Untuk nilai CNR diperoleh dari selisih nilai SNR anatara ventrikel lateral dengan nucleus caudatus, ventrikel lateral dengan capsula interna, thalamus dengan capsula, nucleus caudatus dengan capsula interna, dan putamen dengan capsula interna. Data dari hasil nilai SNR dan CNR akan diolah dan dianalisa secara komputerisasi dengan menggunakan program SPSS. Penilaian SNR dan CNR menggunakan software yang ada di pesawat MRI, hasilnya berupa data rasio. Kemudian data dianalisis dengan ShapiroWilk test untuk mengetahui normalitas data. Apabila data normal dilakukan uji regresi linier untuk mengetahui seberapa kuat pengaruh variasi interslice gap terhadap SNR dan CNR.

Hasil citra MRI brain potongan axial dengan sekuens spin echo pembobotan T1WI dibacakan oleh responden menggunakan kuesioner penilaian kejelasan informasi citra anatomi pada citra MRI brain. Untuk mengetahui perasamaan persepsi antar responden dilakukan dengan uji Cohen's Kappa. Apabila kappa value berada pada rentang 0,61-0,80 maka tingkat persamaan persepsi dinyatakan substansial dan rentang 0,81-1 tingkat persamaan persepsi dinyatakan hampir sempurna. Parameter yang digunakan pada T1WI SE MRI brain pada penelitian ini seperti pada tabel 1 .

Tabel 1. Nilai parameter penelitian

\begin{tabular}{lc}
\hline \multicolumn{1}{c}{ Parameter } & Nilai \\
\hline Time repetition $(\mathrm{ms})$ & 680 \\
Time echo $(\mathrm{ms})$ & 15 \\
NEX & 2 \\
Slice Thickness $(\mathrm{mm})$ & 5 \\
Flip angle & $90^{\circ}$ \\
FOV $(\mathrm{mm})$ & 230 \\
\hline
\end{tabular}

\section{Hasil dan Pembahasan}

Untuk mengetahui pengaruh penggunaan variasi Interslice Gap terhadap kualitas citra, dilakukan uji regresi linear dengan syarat data berdistribusi normal. Hasil distribusi data kualitas citra dan informasi citra dengan Shapiro-Wilk dapat dilihat pada tabel di bawah ini.

Tabel 2. Hasil uji normalitas data SNR dan CNR

\begin{tabular}{ccc}
\hline Kualitas citra & P value & Keterangan \\
\hline SNR & 0.141 & Data normal \\
CNR & 0.506 & Data normal \\
\hline
\end{tabular}

Berdasarkan tabel 2 di atas, diperoleh hasil normalitas data variasi Interlice Gap terhadap nilai SNR dan CNR dinyatakan normal karena setiap data memiliki $p$ value $>0.05$. Dapat dipastikan bahwa untuk uji pengaruh variasi Interlice Gap terhadap SNR maupun CNR menggunakan uji regresi linear. Hasil uji regresi linear dapat dilihat pada tabel 3. 
Tabel 3. Hasil uji Regresi Linear

\begin{tabular}{cccc}
\hline Kualitas citra & R square & P value & Keterangan \\
\hline SNR & 0.203 & 0.010 & $\begin{array}{c}\text { Variasi interslice gap } \\
\text { mempengaruhi SNR } \\
\text { sebesar 20.3\% }\end{array}$ \\
CNR & 0.292 & 0.001 & $\begin{array}{c}\text { Variasi interslice gap } \\
\text { mempengaruhi SNR } \\
\text { sebesar 29.2 \% }\end{array}$ \\
\hline
\end{tabular}

Hasil uji regresi linear variasi Interslice Gap terhadap kualitas citra pada tabel 3, menunjukkan bahwa ada pengaruh antara penggunaan variasi Interslice Gap 0\%, $10 \%, 20 \%$ dan $30 \%$ terhadap nilai SNR dan CNR. Adapun kuat pengaruh variasi interslice gap terhadap SNR sebesar $20.3 \%$ dan kuat pengaruh variasi interslice gap terhadap CNR sebesar $29.2 \%$ dengan $p$ value yang didapatkan $<0.05$. Dari hasil uji regresi linear selanjutnya diperoleh persemaan regresi yang ditunjukkan pada tabel 4.

Tabel 4. Nilai konstanta B dan persamaan regresi

\begin{tabular}{cccc}
\hline $\begin{array}{c}\text { Kualitas } \\
\text { citra }\end{array}$ & B constant & $\begin{array}{c}\text { Koefisien } \\
\text { regresi }\end{array}$ & Persamaan \\
\hline SNR & 160.33 & 12.73 & $\mathrm{y}=160.33+12.73 \mathrm{x}$ \\
CNR & 43.04 & 5.50 & $\mathrm{y}=43.04+5.50 \mathrm{x}$ \\
\hline
\end{tabular}

Arti dari persamaan regresi pada tabel 4 ini adalah nilai B constant pada SNR sebesar 160.33 dengan nilai koefisien regresi 12.73 dapat diartikan bahwa apabila tidak ada interslice gap (nilai interslice gap adalah 0) maka SNR yang dihasilkan sebesar 160.33. Sedangkan koefisien regresi SNR sebesar 12.73 menyatakan bahwa setiap penambahan interslice gap sebesar 10, maka SNR akan meningkat sebanyak 12.73 kali.

Untuk melihat arah dari pengaruh variasi Interslice terhadap kualitas citra memiliki pengaruh positif atau negatif dapat dilihat dari nilai t hitung pada tabel 5 .

Tabel 5. Nilai t hitung

\begin{tabular}{ccc}
\hline Kualitas citra & t hitung & Keterangan \\
\hline SNR & 2.766 & Arah positif \\
CNR & 3.520 & Arah positif \\
\hline
\end{tabular}

Berdasarkan tabel $5 \mathrm{t}$ hitung pada SNR dan CNR yaitu memiliki arah positif, yang berarti semakin tinggi nilai interslice gap, maka SNR dan CNR juga meningkat.
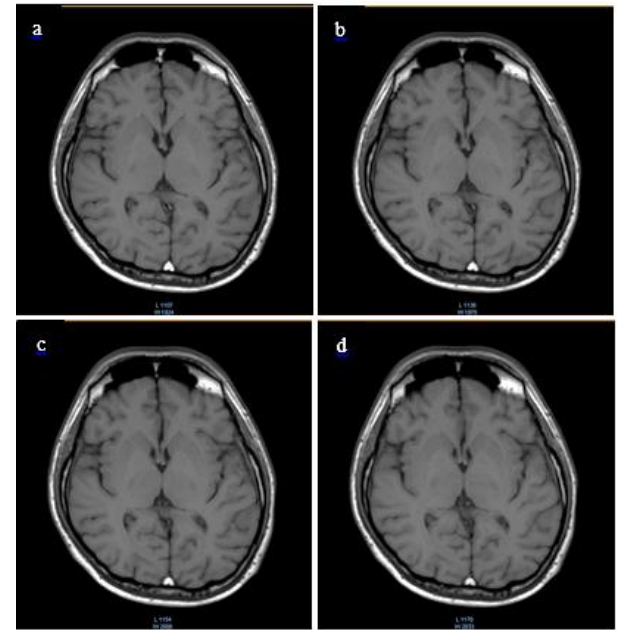

Gambar 1. Citra MRI brain variasi interslice gap sukarelawan 1

Keterangan: $\mathrm{a}=$ variasi interslice gap $0 \%$; $\mathrm{b} .=$ variasi interslice gap $10 \%$; $\mathrm{c}=$ variasi interslice gap $20 \%$; $\mathrm{d}=$ variasi interslice gap $30 \%$;

Data penilaian informasi anatomi MRI brain oleh responden sebelumnya di uji reliabilitas dengan menggunakan uji Kappa untuk melihat konsistensi atau kesepakatan antara kedua responden dalam menilai informasi anatomi.

Tabel 6. Hasil uji Kappa

\begin{tabular}{ccc}
\hline Uji Kappa & Value & Kesimpulan \\
\hline $\begin{array}{c}\text { Responden 1 vs } \\
\text { Responden 2 }\end{array}$ & 0.750 & Reliabilitas baik
\end{tabular}

Berdasarkan tabel 2 hasil dari uji Kappa menunjukkan bahwa terdapat kesepakatan persepsi antara kedua responden dengan nilai Kappa sebesar 0.750 yang berarti memiliki reliabilitas baik, maka untuk uji statistik informasi citra selanjutnya peneliti hanya menggunakan data dari salah satu responden saja. Data yang peneliti gunakan adalah data informasi citra dari responden pertama karena memiliki pengalaman lebih lama dibanding responden 2 .

Uji perbedaan dilakukan untuk melihat perbedaan informasi anatomi citra MRI brain potongan axial T1WI spin echo yang dihasilkan dari penggunaan variasi Interslice Gap .Data informasi citra didapatkan dari Responden yang sebelumnya telah dilakukan uji kappa. Untuk uji perbedaan menggunakan uji Friedman. Hasil uji Friedman dapat dilihat pada table 7 . 
Tabel 7. Hasil uji Friedman

\begin{tabular}{ccc}
\hline Area Anatomi & P value & Keterangan \\
\hline Informasi anatomi & 0.001 & Ada beda \\
\hline
\end{tabular}

Berdasarkan hasil uji statistik non parametrik Friedman pada tabel 7, menyatakan bahwa terdapat perbedaan yang signifikan antara penggunaan variasi Interslice Gap terhadap informasi citra yang dihasilkan, dengan nilai signifikansi $(\mathrm{p}<0.05)$. Untuk mengetahui Interslice Gap mana yang lebih baik dalam mevisualisasikan informasi anatomi pada pemeriksaan MRI brain potongan axial T1WI spin echo dengan penggunaan variasi Interslice Gap, maka dapat dilihat pada tabel 8 .

Tabel 8. Hasil mean rank uji Friedman

\begin{tabular}{ccc}
\hline Variasi interslice gap & Mean rank & Keterangan \\
\hline $0 \%$ & 1.88 & 4 \\
$10 \%$ & 3.94 & 1 \\
$20 \%$ & 2.19 & 2 \\
$30 \%$ & 2.00 & 3 \\
\hline
\end{tabular}

Berdasarkan hasil mean rank uji Friedman pada tabel 8 Menunjukkan bahwa Interlice Gap $10 \%$ memiliki nilai yang lebih tinggi dibanding Interlice Gap lainnya, dengan nilai rata-rata rank sebesar 3.94.

\section{Pengaruh variasi Interslice Gap terhadap kualitas citra pada pemeriksaan MRI brain T1WI spin echo potongan axial ditinjau dari SNR}

Pada hasil analisis uji regresi ini, menunjukkan bahwa ada pengaruh variasi Interslice Gap 0\%, $10 \%, 20 \%$ dan 30 $\%$ terhadap nilai SNR sebesar $20.3 \%$. Sedangkan sisanya, yaitu sebesar $79.7 \%$ SNR dipengaruhi oleh faktor lain. Untuk menentukan hipotesa dilihat dari $p$ value, output dari uji regresi linear menunjukkan nilai $p$ value SNR sebesar 0.010 (p value < 0.05), maka Ho ditolak dan Ha diterima yang berarti terdapat pengaruh variasi interslice gap terhadap nilai SNR.

Menurut peneliti, naiknya nilai SNR dikarenakan saat interslice gap naik, maka TR efektif juga naik, saat TR efektif naik banyak magnetisasi longitudinal yang recovery, sehingga banyak magnetisasi transversal yang terjadi, oleh karena itu sinyal akan naik dan SNR otomatis naik.

Berdasarkan nilai $\mathrm{t}$ hitung, SNR memiliki $\mathrm{t}$ hitung sebesar 3.250, pengaruh variasi interslice gap terhadap SNR memiliki arah positif, yang berarti semakin naik nilai interslice gap, juga akan meningkatkan nilai SNR. Selain dikarenakan TR efektif naiknya SNR juga disebabkan oleh cross-talk, saat interslice gap naik maka cross-talk turun, cross-talk terjadi karena proses slice selective profile tidak berbentuk persegi melainkan berbentuk gausian, sehingga antar slice profile yang saling berdekatan (interslice gap kecil) memiliki area yang saling overlapping (bertumpukkan), pada area yang overlapping tersebut sinyal tersaturasi, sehingga semakin besar cross-talk, sinyal semakin sedikit, karena banyak sinyal yang tersaturasi.

Ketidaktetapan nilai SNR pada organ dapat disebabkan karena komponen hardware dalam MRI, software dan juga obyek. Hardware dari komponen MRI misalnya magnet utama, shim coil, gradient coil, $R F$ coil ataupun dari komputer. Apabila beberapa hardware tadi tidak terawat dan terkalibrasi dengan baik, maka kemungkinan kekuatan medan magnet yang dihasilkan dan tingkat homogenitas medan magnet akan menurun, sehingga sinyal akan menurun. Apabila penurunan sinyal tidak disertai dengan penurunan noise, maka SNR juga akan menurun.

Obyek / pasien juga berpengaruh besar terhadap timbulnya noise. Salah satu sumber noise yang signifikan adalah pasien. Tiap kali proton berubah (turun) dari energi tinggi ke energi rendah, akan mengemisi foton (gelombang radio) dengan phase random dan akan berkontribusi terhadap background noise (NessAiver, 1996). Hal ini juga dapat dimungkinkan apabila terjadi pergerakan pada pasien, dimana terjadi aktivitas perubahan energi akan berimbas pada kontribusi noise pada citra MRI.

Menurut Scwaighofer, dkk (1989) sinyal naik ketika nilai interslice gap naik, karena terjadi penurunan cross-talk yang mempengaruhi sinyal pada area yang saling overlapping.

\section{Pengaruh variasi Interslice Gap terhadap kualitas citra pada pemeriksaan MRI brain T1WI spin echo potongan axial ditinjau dari CNR}

Berdasarkan uji regresi, menunjukkan bahwa ada pengaruh antara penggunaan variasi Interslice Gap 0\%, 10 $\%, 20 \%$ dan $30 \%$ terhadap nilai CNR sebesar $29.2 \%$. Sedangkan sisanya, yaitu sebesar $70.8 \%$ SNR dipengaruhi oleh faktor lain. Untuk menentukan hipotesa dilihat dari $p$ value, output dari uji regresi linear menunjukkan nilai $p$ value CNR sebesar 0.001 ( $\mathrm{p}$ value < 0.05), maka Ho ditolak dan Ha diterima yang berarti terdapat pengaruh variasi interslice gap terhadap nilai CNR.

Berdasarkan nilai $\mathrm{t}$ hitung, CNR memiliki $\mathrm{t}$ hitung sebesar 2.766, pengaruh variasi interslice gap terhadap CNR memiliki arah positif, yang berarti semakin naik nilai interslice gap, juga akan meningkatkan nilai CNR.

Menurut peneliti peningkatan CNR seiring dengan peningkatan nilai interslice gap disebabkan karena faktor yang sama dengan yang menyebabkan kenaikan SNR, sebab CNR merupakan selisih antara SNR objek yang saling berdekatan.

Ketidaktetapan nilai SNR pada objek dapat disebabkan oleh komponen hardware dalam MRI, software dan juga obyek akan dapat mengakibatkan ketidaktetapan nilai CNR juga karena CNR merupakan selisih antara SNR pada objek yang berdekatan, sehingga nilai CNR juga bergantung pada nilai SNR (Westbrook, 2008). 
Menurut Westbrook,dkk. (2011) perbedaan SNR antara dua area yang berdekatan, CNR juga dikontrol oleh faktorfaktor yang mempengaruhi SNR. Semua pemeriksaan harus menghasilkan gambaran CNR yang bagus antara patologi dengan area anatomi normal. Dalam hal ini, CNR dapat ditingkatkan dengan cara menggunakan media kontras, menggunakan pembobotan $\mathrm{T} 2$, penekanan jaringan normal menggunakan sekuen yang menghilangkan sinyal dari jaringan tertentu, Penggunaan sekuen untuk penyangatan aliran (enhanced flow). Selain itu menurut Woordward (1998), kontras dalam MRI adalah perbedaan tingkat kecerahan relatif antar pixel, sebagai hasil dari intensitas sinyal yang di terima oleh setiap pixel selama proses pencitraan berlangsung. Perbedaan intensitas sinyal disebabkan oleh perbedaan tingkat relaksasi spin. Kontras dipengaruh oleh jenis pulsa sekuen, TR (Time Repetition),TE (Time Echo), TI (Time Inversion), FA (Flip Angle), nilai T1 dan T2, Densitas Hidrogen, dan Pemakaian bahan kontras.

Perbedaan variasi Interslice Gap terhadap informasi citra anatomi pada pemeriksaan MRI brain T1WI spin echo potongan axial

Pada uji Friedmen ini menyatakan bahwa terdapat perbedaan yang signifikan antara penggunaan variasi Interslice Gap terhadap informasi citra yang dihasilkan, dengan nilai signifikansi $\mathrm{p}<0.05$, maka berarti menunjukan bahwa Ho ditolak dan Ha diterima. Artinya ada perbedaan yang signifikan pada informasi anatomi citra anatomi MRI brain potongan axial T1WI spin echo dengan variasi Interslice Gap.

Berdasarkan uji Friedmen Test diatas juga diperoleh nilai mean rank pada masing - masing perlakuan. Informasi citra anatomi MRI brain potongan axial T1WI spin echo dengan variasi Interslice Gap $0 \%$ adalah 1.88, Interslice Gap $10 \%$ adalah 3.94, Interslice Gap $20 \%$ adalah 2.19, Interslice Gap $30 \%$ adalah 2.00. Berdasarkan nilai mean rank tersebut menunjukan bahwa Interslice Gap $10 \%$ memiliki nilai mean rank paling tinggi yang berarti merupakan nilai Interslice Gap paling optimal dari variasi yang telah dilakukan.

Menurut peneliti, adanya perbedaan informasi anatomi MRI brain potongan axial T1WI spin echo dengan variasi interslice gap karena semakin naiknya nilai interslice gap ada informasi anatomi yang tidak tampak, karena ada pada celah (gap) tersebut. Nilai interslice gap yang memiliki informasicitra anatomi yang optimal berdasarkan penelitian ini yaitu interslice gap $10 \%$, hasil ini berbeda dengan kualitas citra karena untuk penilaian informasi anatomi sangat subjektif karena tregantung oleh pengelihatan responden, beberapa orang barangkali tidak akan memperhatikan noise background tinggi jika resolusi pada daerah tersebut juga tinggi.

Menurut Hashemi (2010), Peningkatan interslice gap dapat menyebabkan meningkatnya coverage, menurunkan cross-talk, menaikkan SNR (karena meningkatnya TR efektif dengan menurunkan cross-talk) dan menurunkan deteksi pada lesi yang kecil, karena berada pada gap tersebut.

\section{Simpulan}

Terdapat pengaruh variasi Interslice Gap terhadap kualitas citra pada MRI brain potongan axial T1WI spin echo, ditinjau dari SNR dan juga CNR yang memiliki $\mathrm{p}$ value $<0.05$. Variasi Interslice Gap terhadap SNR memiliki pengaruh sebesar $20.3 \%$, Variasi Interslice Gap terhadap CNR memiliki pengaruh sebesar $29.2 \%$.

Ada perbedaan informasi citra anatomi MRI brain potongan axial T1WI spin echo dengan variasi Interslice Gap dilihat dari nilai $\mathrm{p}$ value $<0.05$ yang berarti memiliki perbedaan yang signifikan.

Nilai variasi Interslice Gap $10 \%$ memiliki informasi citra paling optimal berdasarkan mean rank dari uji Friedman dengan nilai rata-rata rank sebesar 3.94.

\section{Daftar Pustaka}

Chrysikopoulos, Haris S., 2009, Clinical MR Imaging and Physics, Springer, Verlag Berlin Heidelberg

Hashemi, H. Ray and Bradley, G. William, 2010, MRI : The Basic third edition, Williams \& Wilkins, Philadelphia, USA

Hiatt James L. dan Leslie Gartner, 2010, Textbook of Head and Neck Anatomy fourth edition, Lippincott Williams \& Wilkins, Walnut Street, Philadelphia

Kneeland dkk, 1986, Effect of Intersection Spacing on MR Image Contrast and Study Time, Department of Radiology, Milwaukee County Medical Complex, West Wisconsin Avenue, Milwaukee.

Mark A. Brown, Ph.D., Richard C. Semelka, M.D., 2003, MRI : basic principlesand applications. John Wiley \& Sons, Inc., Hoboken, New Jersey.

Moeller, Torsten B. dan Emil Reif, 2003, MRI Parameters and positioning, Georg Thieme Verlag, Stuttgart,Germany

Moeller, Torsten B. dan Emil Reif, 2007, Pocket Atlas of SectionalAnatomy Computed Tomography and Magnetic Resonance Imaging Head and Neck Volume I, Georg Thieme Verlag KG, Stuttgart,Germany

NessAiver, 1996, All you really need to know About MRI Physics, University of Maryland Medical Center, USA

Neseth, R. 2000, Procedures and Documentation for CT and MRI, McGraw-Hill, Medical Publishing Division, USA Noback dkk, 2005, The Human Nervous System Structure and Function sixth edition, Humana Press, Totowa, New Jersey

Reimer dkk, 2003, Clinical MRI Imaging second edition, Springer Berlin, Heidelberg

Scwaighofer dkk, 1989, Diagnostic Significance of Interslice Gap and imaging Volume in Body MR Imaging, Department of Radiology, University of California, San Diego. 
JURNAL RADIOGRAFER INDONESIA, ISSN 2620-9950

Westbrook, Cathrine, 2014, Handbook of MRI Technique fourth edition, Willey Blackwell, West Sussex, UK.

Westbrook dkk, 2011, MRI in practice fourth edition, illey Blackwell, West Sussex, UK. 